\title{
EN TORNO A LA REFORMA AGRARIA
}

\author{
Eduardo Hamuy
}

* Instituto de Sociología. Universidad de Chile. C.1958. 



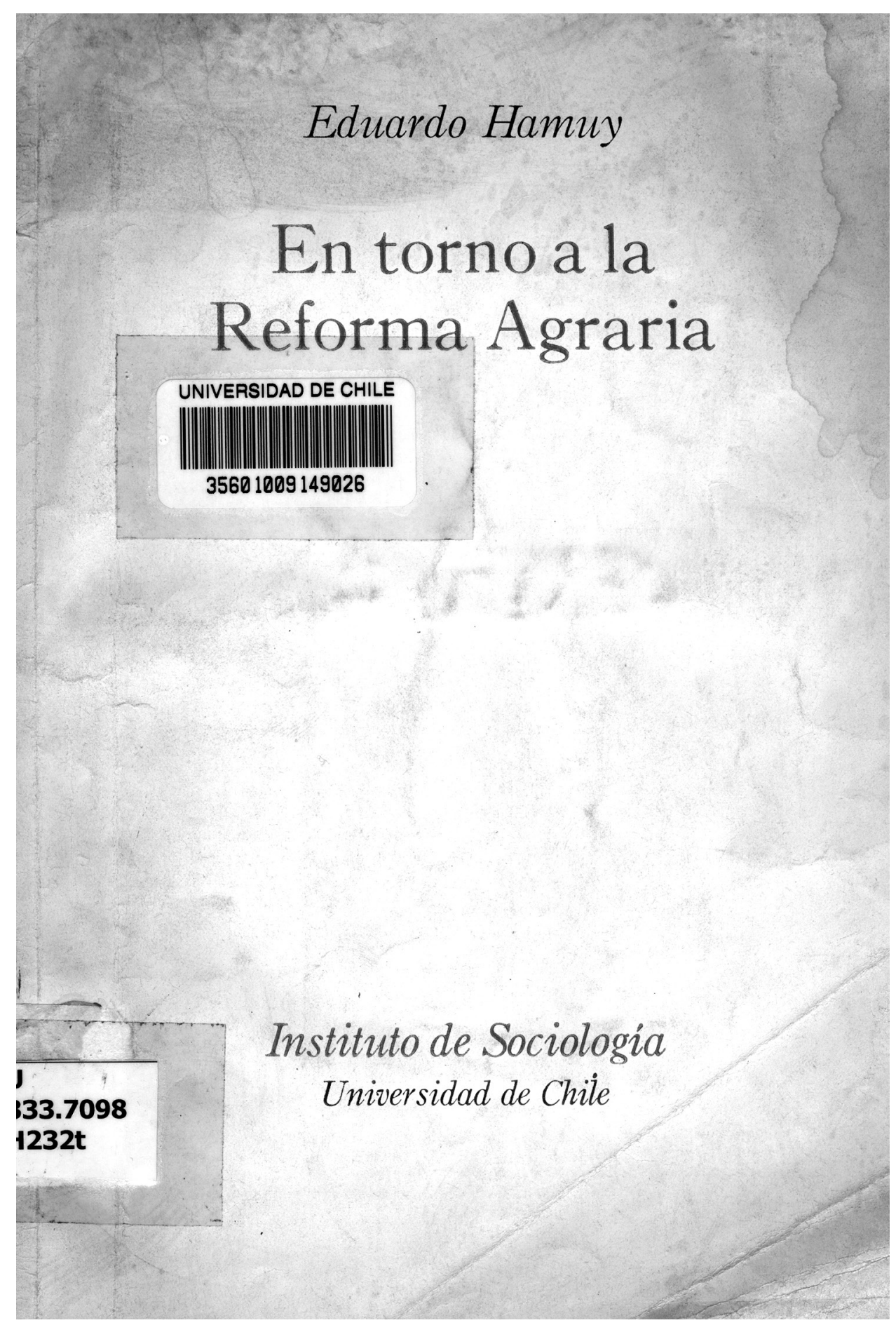




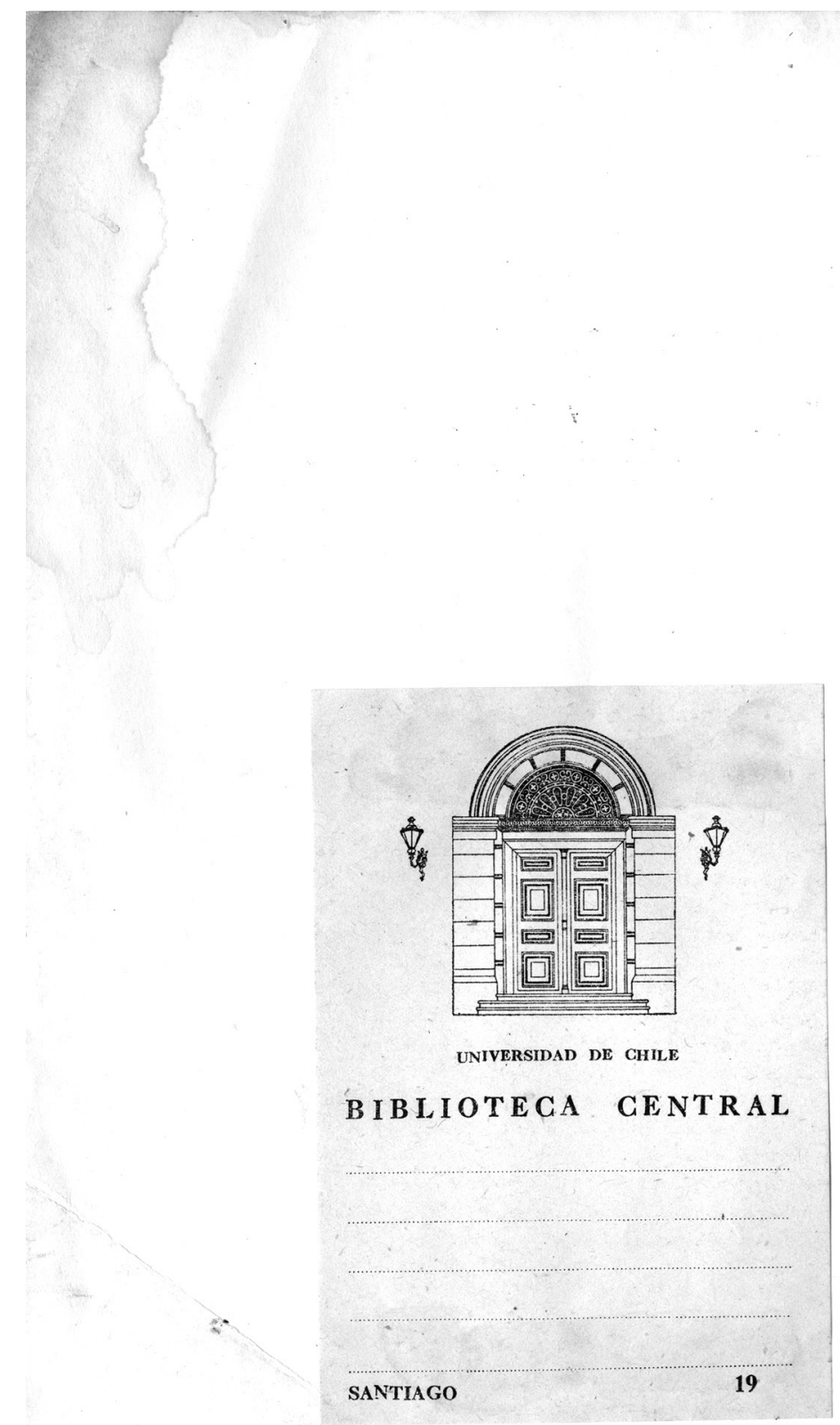




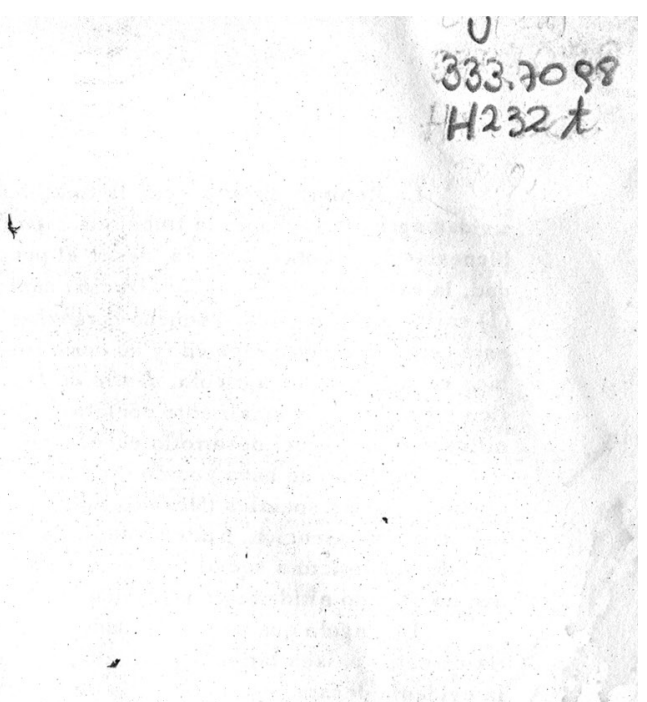

\title{
CONSIDERACIONES SOCIOLOGICAS EN TORNO A LA REFORMA AGRARIA EN LATINO AMERICA*
}

\author{
Por EDUARDO HAMUY \\ Instituto de Sociología * Universidad de Chile.
}

No vamos a insistir en la idea de que la Reforma Agraria es - antes que nada - un problema social y desp ués un problema "técnico" o de los "técnicos". Como es evidente, la Reforma Agraria implica un cambio en la estructura social, una alteración profunda de las relaciones tradicionales de propiedad $y$, por lo tanto, de los modos de interacción social.

Un programa de Reforma Agraria supone, en algún grado, - explícita o impli citamente - una teoría de la sociedad, o por lo menos, y para decirlo en términos más en boga, una teoría del desarrollo económico, la cual exidentemente no es sino un aspecto singular de una teoría general del cambio social. Por esta razón, notiene mucho sentido hablar de Reforma Agraria sin referirse a las condiciones objetivas generales de la sociedad. Es preciso advertir, además, algo que podría parecer obvio: que de la situación histórico-cultural concreta de la sociedad no sólo depende el sentido de la Reforma Agraria, sino su propia posibilidad real. Se podrá decir, entonces, que a veces la Reforma Agraria está en la "orden del día" y que a veces es una mera construcción de "técnicos" o ideólogos.

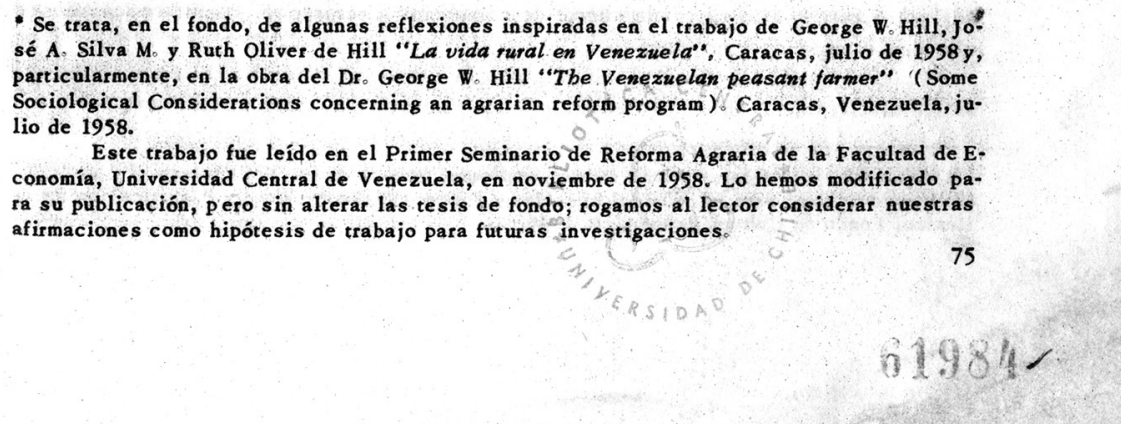


La Reforma Agraria - con la finalidad que le es propia de aumentar la productividad agrícola mediante la transformación de la propiedad rural con vista a elevar el bienestar de la población - es, desde el punto de vista de la estructura de la sociedad, la extensión de la racionalización capitalista a la agricultura. Es lo que Lenin (1) califició de "medidas pequeño-burguesas", justamente porque la Reforma Agraria está concebida como reforma (y no como revolución) en el sentido de introducircambios en la propiedad agrícola, dentro de los marcos del capitalismo, de un modo pacifico y evolutivo, generalmente conforme a un programa específico integrado a una planificación global del desarrollo económico.

Que esto no haya podido hacerse nunca en Latino-América sino recurriendo a cruentas luchas sociales (México, Bolivia, Cuba) es un punto que merece ser considerado con gran atención, p ues su análisis podría revelar alguna característica esen cial de la estructura social (estructura del poder, probablemente) de estos países que aún no ha sido nítidamente percibida.

Un ángulo que parece fecundo para considerar el problema de la Reforma Agraria en estos países latino-americanos, es reconocer, de partida, el hecho históricode la evidente desarmonía o asimetría de los cambios sociales que ocurren en las diversas sociedades humanas, lo cual genera el fenómeno de la coexistencia de socieda. des que se encuentran en muy diverso grado de desarrollo (los llamados paises desarrollados y paises subdesarrollados). La creciente interdependencia de las naciones del globo le confiere cada vez más importancia a este hecho que Mannheim (2) caracteriza como "la coetaneidad de lo no coetáneo".

Es una lástima que no haya sido aún suficientemente analizada la influencia de los paî́ses llamados "desarrollados" sobre aquellos que recién están cumpliendo las etapas que los primeros alcanzaron hace mucho tiempo (en algunos casos, centurias), porque casi no hay un problema de importancia en estas sociedades "tradicionales" (o subdesarrolladas) en el cual no intervenga este factor deformador del proceso "natural" de formación histórica de tales sociedades.

En otras palabras, se sugiere que la constante y multifacética acción de las sociedades "modernas" sobre las "tradicionales", ha deformado notoriamente la estructura social de éstas y ba limitado sus alternativas de cambio. La deformación más grave es la ruptura del continuo social y la estructuración de dos sociedades diferentes - la urbana y la rural - una, relativamente moderna y la otra, francamente tradicional. No se trata que esta diferencia rural-urbana no se produzca en todos los países del mundo; es que aquí hay una ruptura o escisión del contínuo social y la formación de dos estructuras sociales cualitativamente distintas, a pesar de cualquier grado de interpenetración que pudieran tener. Este fenómeno resalta nítidamente al compararel área rural con los centros urbanos mayores (las capitales de los países latino-americanos, por ejemplo). La consecuencia más importante que se desprende de esta extrema asincronia social, es que la Reforma Agraria pasa a ser - de hecho - un programa catastrófico de cambios sociales, una verdadera revolución, es decir, la quiebra de una estructura social con toda suerte de complejas alteraciones y consecuencias en el orden económico y político.

Otro hecho histórico que indica que la estructura social rural es cualitativa mente distinta de la urbana (y no meramente $\mathrm{p}$ untos en el mismo contínuo), es la ex-

(1) Véase "La cuestión agraria". Obras completas, Buenos Aires, Ed. Cartago, 1958.

(2) Mannheim tomó esta förmula del historiador Pinder. Véase Libertad y Planificación Social México, Fondo de Cultura Económica, 1946. 
tremada lentitud del proceso de racionalización de la agricultura en aquellos países donde el cambio de la estructura rural tradicional comenzó mediante una revolución (casos de México y de la URSS). Significa ésto que la resistencia al cambio no sólo proviene de los "intereses creados" (latifundistas, por ejemplo) sino del conjunto de la población campesina, por la razón que ésta tiene profundamente internalizadas las normas que configuran la estructura social tradicional. Parece claro que se puede variar las condiciones objetivas (1) (ej.: redistribuir la propiedad agrícola) mediante enérgicas $y$, aún, violentas medidas, pero que, sin embargo, no se eleve el nivel de racionalidad de la agricultura hasta tanto no se haya influído eficazmente en la motivación y orientación de la acción del campesino, es decir, hasta tanto no se haya cumplido el proceso de re-socialización del hombre del campo.

En el fondo se trata de resolver el problema de que la población rural realice el tránsiro de la acción tradicional a la acción racional (2). El cambio de las motivaciones y valores (orientación de la acción) es un lento proceso que ya lleva 40 años en la URSS y algo más en México (3).

Surge aquí la cuestión de si la comprensión de que en el cambio de la estructura agricola participan factores "objetivos" y "subjetivos" y que ambos son condiciones de una agricultura racional, podría acortar el proceso de cambio, al operarse planificadamente en ambos "frentes". En relación con los factores "subjetivos"(motivaciones, ideologías, valores, conocimientos, etc.) un programa de educación - muy de fondo - sería indispensable. No podemos aquí entrar en este aspecto tan crucial del problema y nos limitaremos a indicar que la efectividad de un programa de educación rural dependerá - en alto grado - de la correcta perspectiva sociológica que lo informe. Si miramos el problema desde los factores "objetivos", uno de los efectos principales que se percibe es que la Reforma Agraria cambia sustancialmente la estructura de poder de una sociedad. $Y$, naturalmente, los "perjudicados", los tradicionaies latifundistas, como lo testimonia la historia una y otra vez, oponen una resis. tencia muy fuerte y muy decidida. Los grandes propietarios de la tierra tienen - generalmente - el apoyo de una gran parte de las Fuerzas Armadas, de un sector de la Iglesia, de las empresas capitalistas extranjeras y de las empresas monopolistas naciona-

(1) El concepto de "condiciones objetivas" está usado en el sentido marxista.

(2) Acción (y sus modos) está usado en el sentido que le da Max Weber. Véase "Economía y Sociedad". V. I, México, Fondo de Cultura Económica, 1944.

(3) China, al parecer, es una excepción por cuanto en pocos años ha incrementado notablemente la producción agrícola. El caso de China pone de relieve que la re-socialización del campesino, es decir, el cambio de la estructura de la acción social, es una condición indispensable de la "reforma"' de la agricultura.

Léase el siguiente párrafo que es parte de un artículo que apareció en "L.e Monde" (octubre, 1958) y cuyo autor es René Dumont:

"Debido al excesivo autoritarismo y a los precios demasiado bajos, la URSS hasta 1953 y las Democracias Populares hasta la fecha, han fallado en una gran medida en su politica agraria. La reacción de los campesinos chinos, enfrentados con la colectivización masiva en el invierno de 1955-1956, constituye hasta ahora un enigma. Sin la participación activa y voluntaria de la mayoría, las montañas no habrían sido terraplenadas, y los terraplenes no hubieran sido mantenidos en su lugar por la grava, y la grava no hubiera sido transportada en la espalda, canasto por canasto desde el lecho de los ríos. Mi impresión es que el Partido Chino ha tenido éxito al unir su autoridad, y el acuerdo de los campesinos después de la debida deliberación ; acuerdo obtenido mediante prolongadas "explicaciones". (Panorama Económico, N 199).

Parece que Cuba también ha logrado éxito en la tarea de "motivar" al campesino para las nuevas y difíciles tareas que la Revolución ha impuesto; el Gobierno cubano se ha propuesto, en primer lugar, el objetivo de mantener la producción agrícola de la época prerevolucionaria. (Véase: CEPAL, La Reforma Agraria Cubana, Panorama Económico, No 214). 
les. A las empresas extranjeras les interesa especialmente disponer de mano de obra barata y de privilegios. Una sociedad dinámica representa la inevitable perspectiva de un tratamiento más racional y, por lo tanto, de concesiones que se consideren "razonables" en términos capitalistas. La sociedad tradicional, en cambio, es bastante menos exigente porque sus necesidades (la del grupo social dominante) son relativamente pequeñas, ya que los problemas del desarrollo apenas se plantean. El pago de regalías por parte de las empresas extranjeras, además de los privilegios de otro orden, (renta de la tierra, etc.), convierte a una buena parte de los latifundistas en rentistas o semi-rentistas. En este sentido, los gobiernos dictatoriales son los más convenientes. Esta conveniencia consiste específicamente en tratar los negocios en la forma de "concesiones", muy alejadas del racionalismo capitalista y cuenta con el sistemático apoyo de los gobiernos de las grandes potencias industriales, los cuales, por esta vía, agudizan la asincronía entre los países desarrollados y subdesarrollados, al apoyar la sociedad tradicional y resistir los cambios, pero, a la vez, favoreciendo los mismos en el interior de sus propios países (1).

Otra importante expresión de asincronía social se produce en el plano político: los países subdesarrollados adoptan instituciones políticas como el sufragio universal (y en general todo un formalismo democrático) que en los países industriales (sociedades modernas) se lograron después de un largo proceso "natural". En estos últimos países las instituciones modernas surgen "desde dentro". En los países subdesarrollados es muy frecuente que el sufragio universal favorezca a los grandes propietarios de la tierra porque la acción política tiene una motivación preponderante mente tradicional. El voto rural es generalmente conservador. La misma característica tiene el voto de las mujeres.

Pese a que las formas democráticas que se imitaron son las que pertenecían a países capitalistas "maduros", aquellas no han favorecido particularmente el proceso de racionalización de la agricultura. Es decir, no han sido eficaces. Tal vez en general - más bien han sido factores de resistencia al cambio en lo referente a la agricultura, ya que los opositores a la Reforma Agraria se eligen justamente con votos campesinos.

El formalismo democrático de estos países es un factor que no puede estarausente del análisis y que está muy relacionado con el problema que planteabamos de la posibilidad real de la Reforma Agraria por las vías evolutivas y pacíficas. Sería necesario realizar estudios especiales sobre este aspecto del problema.

El apoyo lógico a la Reforma Agraria debería provenir del sector capitalista nacional y de los obreros industriales. Sin embargo, en relación con ésto, la situación en muchos de los países de América Latina dista de ser simple. El modelo clásico de desarrollo económico capitalista según el cual el fortalecimiento del sector industrial - empresarios y obreros - presiona sobre la estructura tradicional de la agricultura y la modifica en consonancia con el racionalismo capitalista '( Reforma A- graria), nunca ha funcionado bien en América Latina. México, Bolivia y Cuba rompieron la tradicional fisonomía de la propiedad agraria por la actuación de factores que no estuvieron directamente relacionados cơn el nivel de desarrollo industrial. Dichos -países se encontraban en un nivel de desarrollo económico bastante más bajo que ootros de este continente. De aquí se desprende, entonces, un serio problema: el de

(1) A nuestro juicio, el apoyo político de los gobiemos de los países industriales a sus empresas en Latino-América que están basadas en "concesiones" y "privilegios" ajenos al racionalismo capitalista, explica la poca simpatía de los Estados Unidos hacia organismos como la CEPAL y, por otra parte, el apoyo constante que le ha prestado a las dictaduras.

78 
cuáles son los factores económicos, sociales y políticos que condicionan la Reforma Agraria, si la historia testimonia que el modelo clásico no se reproduce en Latino-América.

Por otra parte, la resistencia al cambio del sector propietario es tan fuerte que - hasta el momento - los ejemplos que poseemos (México, Bolivia, Cuba) revelan que la Reforma Agraria se realiza cuando se produce la crisis política de toda la sociedad.

¿Porqué ésto es así? Probablemente porque las fuerzas sociales (grandes propietarios) cuyo poder está basado justamente en la agricultura, no han encontrado en términos de poder social - la adecuada compensación que les permita renunciar a los privilegios que obtienen de una agricultura atrasada. La "modernización" de la agricultura - sobre la base de sus propios predios y de ellos mismos como :empresarios (1) - no es para la clase de los latifundistas una buena solución, p orque perderían su posición estratégica en la estructura de poder de toda la sociedad. Planteadas asi las cosas, la salida de esta situación no puede ser sino catastrófica.

En cambio, fácilmente se ha encontrado un mecanismo de compensación para los capitalistas nacionales. Los intereses opuestos de éstos a los de los latifundistas se concilian concediendo las ventajas monopolistas en el mercado y otros privi legios económicos que son de resorte del gobierno, en lugar de la "extensión" del mercado al área rural; además, de la participación en el poder político y aún, del acceso a ciertos grupos estamentales. Como generalmente en estos países hay ausencia de espectativas económicas brillantes, aún abriendo el mercado rural, el capitalismo criollo se deriva hacia la fácil y cuantiosa utilidad que resulta del monopolio yotros privilegios (cambios preferenciales, autorización para importar, retornos, etc。) y como, al mismo tiempo, carece de una moral de trabajo (una definida ideología de clase - ascetismo capitalista), no tiene dificultad en adoptar las normas morales de la clase alta tradicional, imitar su "estilo de vida" y asociarse a ésta en negocios bancarios, sociedades anónimas, etc。

Esta clase de transacciones siempre encuentran el apoyo de las empresas extranjeras y de sus respectivos gobiernos, quienes a menudo facilitan medios para que tales alianzas sean posibles. Esta actitud de las empresas y de sus gobiernos es perfectamente racional; sus privilegios están estrechamente asociados a la irracionali dad de la sociedad tradicional.

La falta de una "ascesis capitalista" (2), por una parte, y de una ideología de clase en la que los empresarios basen su pretensión de legitimidad del poder, debilita el proceso de desarrollo industrial, y, en consecuencia, a la clase capitalista y disminuye - si no elimina - la presión sobre la estructura rural tradicional. Si lo primero ataca el ahorro y la capitalización, lo segundo conduce a una inseguridad en los tratos con la clase tradicional, la cual aparece hasta ahora con más títulos para ejercer el poder que las nuevas clases; su ideología de clase está más cimentada y usa todos los elementos tradicionales para alegar la legitimidad de su poder. Frente a esta clase la burguesía nacional es débil, vacilante e inclinada, por lo tanto, al compromiso político y económico. Un factor que acentúa esta vacilación es el apoyo de las grandes potencias a la clase tradicional; no hay muchas evidencias que EE. UU. por ejemplo, mire con especial simpatía los esfuerzos nacionales por el desarrollo económico y, en cambio, hay muchas evidencias de que prefiere en el poder a la clase tradicional, sea con un dictador o sea con un presidente formalmente electo.

(1) Modelo junker.

(2) Véase Max Weber: "Etica protestante" y el espíritu del capitalismo". Madrid,Rev. de Derecho Privado. 
Se crea así otra peculiar asincronía de estas sociedades latinoamericanas: la contradicción entre el carácter de la producción y la del consumo. Este último tiene en la clase alta tradicional el carácter de "conspicuo" u ostentoso (en el sentido que le da Veblen (1)); este estilo de vida se ha institucionalizado como símbolo de alto status social y ha sido heredado por los capitalistas criollos. Por supuesto que no hay relación entre el refinamiento de tal estilo de vida y el nivel primitivo de desarrollo económico de estas sociedades. Como se dijo, tal consumo (grandes mansiones, automóviles, vestimenta, viajes, etc.) limita seriamente el volumen de los ahorros y el proceso, por lo tanto, de acumulación capitalista. Esta situación es, naturalmente, más seria en los países tan pobres como Chile.

La falta de una "ascesis" capitalista profundamente institucionalizada unida a un mercado limitado que deviene monopolista, es la base social de tal consumo desenfrenado e irresponsable. El ascetismo del empresario latino-americano existió mientras formaba su capital, "se hacía su situación". Este ascetismo inicial a menudo se expresó en enormes sacrificios personales, en la privación de lo elemental, incluso en la limitación de su alimentación (2), etc.; sin embargo, rápidamente el ascetismo se transformó en su contrario en cuanto el empresario "hizo fortuna".

Es del caso discutir aquí cuán general es este ascetismo inicial entre los empresarios y el carácter que tiene. Aparentemente, es el inmigrante el que realiza más sacrificios iniciales en el consumo y esto es más bien explicable por la necesidad que tienen todos los inmigrantes de integrarse socialmente y ocupar una posición sólida que elimine su natural inseguridad. La lucha por ascender socialmente los lleva a acumular riquezas y a consumirlas conspicuamente. Quede claro, entonces, que no se trata de un ascetismo capitalista como el de los grandes países industriales, sino de una necesidad material y social de carácter temporal. No hay una moral ascética porque de haberla habido, la sobriedad de las costumbres se hubiera mantenido basada en el deber moral de continuar el proceso de capitalización (y de transformación de la estructura social tradicional), en nombre del bienestar general de la colectividad.

$\mathbf{Y}$ aquí nuevamente tropezamos con otra grave asincronía. Países que quieren seguir la senda de las grandes potencias capitalistas pero sin una ideología capitalista que sea exhibida por los empresarios como la solución de los problemas generales de la sociedad, como un bien, y a la vez, que obligue a los empresarios a ser"modelos" y ejemplos en la sociedad, es decir, a tomar con decisión el rol de dirigentes y a hacerse responsable del bienestar social. Esta es una de las condiciones para que sea posible el desarrollo económico dentro de los marcos de la estructura capitalista.

¿Cuál sería el factor que podría reemplazar la ideología capitalista que se basó en la ética protestante, de modo que cumpliera la misma función social (legitimación del poder, ascetismo, principios de acumulación?). El rol que tuvo la iglesia protestante en Alemania e Inglaterra en la maduración del capitalismo solamente puede desempeñarlo en Latino-América - y muy atenuadamente - el sistema educacional。 La condición necesaria para que el sistema educacional cumpla tal función, es que los empresarios logren el poder político sin contrapeso y cambien enérgicamente los contenidos valorativos de la educación, la cual tendría que estar consecuentemente al servicio de la construcción del capitalismo. Aún así no se podría pretender que ten-

(1) "Teoría de la clase ociosa", México, Fondo de Cultura Económica, 1944.

(2) Un interesante documento social es, en este sentido, la obra de Benedicto Chuaqui, "Memorias de un inmigrante". Santiago, Chile, Ed. Nascimento, 1957.

80 
ga la fuerza de la religión. Hoy día, en Chile y probablemente en toda Latino-América, la educación privada que atiende al sector más privilegiado de la sociedad,acentúa y fomenta el consumo conspicuo y todas las formas simbólicas de prestigio social. Es decir, es tradicional y anti-capitalista.

Agregemos que el consumo conspicuo de las clases dirigentes no encuentra suficiente censura de parte del pueblo, sobre el cual pesa mucho el tradicional paternalismo de las relaciones sociales. La alienación de los fines de la educación es uno de los puntos de deformación de estas sociedades, que ahonda y agudiza la asincronía de producción y consumo. Una educación al servicio de la sociedad trataría de internalizar en los sujetos la idea que el consumo conspicuo es anti-social y que debe ser motivo de censura más bien que fuente de prestigio social.

El otro factor que puede con igual éxito reemplazar a la ética protestante es la mística socialista (1) si el desarrollo se realiza, naturalmente, en los marcos de una sociedad que pretendiera ser socialista. Los problemas del desarrollo económico de estas sociedades se ven teóricamente más facilmente resueltos cuando el modelo es el socialismo y no el capitalismo. Pero no podemos discutirlo aquí porque el própósito de este artículo fue discutir el condicionamiento social de unos ciertos cambios (Reforma Agraria) que se realizarían “dentro'” de los marcos capitalistas.

(1) "Socialista" está tomado en su sentido más amplio, como cualquiera solución colectivista, no-capitalista. 